\title{
An Integrative View of IS/IT and Organizational Resources and Capabilities
}

\author{
Sergio Araya \\ Universidad Politécnica de Madrid (UPM), Madrid, Spain and \\ Universidad del Bío-Bío, Concepción, Chile
}

\author{
Julián Chaparro, Alejandro Orero, and Hernán Joglar \\ Grupo de Ingeniería de Organización, Escuela Técnica Superior \\ de Ingenieros de Telecomunicación, Universidad Politécnica de \\ Madrid (UPM), Madrid, Spain
}

\author{
saraya@gio.etsit.upm.es chaparro@gio.etsit.upm.es \\ aorero@gio.etsit.upm.es hjoglar@gio.etsit.upm.es
}

\begin{abstract}
Different studies in the context of information systems and information technologies (IS/IT) support the idea that these resources may contribute to develop competitive advantages and to improve organizational performance. To accomplish such benefits, IS/IT resources must be combined with some other organizational elements. Although the necessary relationships are recognized in literature, integration of IS/IT resources and other organizational elements have not been theoretically developed. Based on the resource-based view of the firm, this paper proposes an integrated view of what we call "resources and capabilities associated to IS/IT". Our approach is focused on all organizational resources and capabilities (within and without IS/IT area) that are related or are necessary to efficient and effective IS/IT development and utilization.
\end{abstract}

Key words: Resources and capabilities, information systems, information technologies.

\section{Introduction}

Information systems and information technologies (IS/IT) have usually been regarded as technological resources. As such, they are supposed to be backed by other elements, namely organizational resources and capabilities, to actually provide significant contribution, especially at the strategic level. Though recognizing the necessary relation among both factors, specialized literature analyzes their interactions in a non integrated fashion, while presenting them as linkages between two separate domains.

Material published as part of this publication, either on-line or in print, is copyrighted by the Informing Science Institute. Permission to make digital or paper copy of part or all of these works for personal or classroom use is granted without fee provided that the copies are not made or distributed for profit or commercial advantage AND that copies 1) bear this notice in full and 2) give the full citation on the first page. It is permissible to abstract these works so long as credit is given. To copy in all other cases or to republish or to post on a server or to redistribute to lists requires specific permission and payment of a fee. Contact Publisher@InformingScience.org to request redistribution permission.

In this context, this article presents an integrative perspective of the elements mentioned above, that is, we incorporate those factors that are usually identified as pertaining to the IS/IT area along with the ones that are considered as supporting elements. We have designated this combination as "resources and capabilities associated to IS/IT". 
Accordingly, the objective of this research is to identify a feasible conceptual integration among factors usually identified as related to organizational IS/IT resources and capabilities and other firm's resources and capabilities. This combination should enable us to formulate a definition and to propose a classification of the integrated elements.

\section{Methodological Approach}

(i) Review the literature related to IS/IT, using an overall approach based on the Theory of Resources and Capabilities.

(ii) Perform an identification and analysis of concepts and characteristics associated to resources and capabilities in the IS/IT area, in order to advance a conceptual development.

(iii) Carry out an identification and analysis of the various resources and capabilities related to IS/IT so as to bring about a classification of them.

\section{Organizational Resources and Capabilities}

During the last decade, studies on organizational strategic development have paid special attention to the available resources and capabilities (Barney, 2002; Bharadwaj, 2000; Bhatt, 2000; Dreyer \& Gronhaug, 2004; Grant, 1996; Medina, 1998; Ventura, 1996). These elements have been considered as essential assets that enable organizations to attain competitive advantages and influence organizational performance.

Resources and capabilities analysis attempts to explain why companies in the same sector, which face the same competitive environment, often have different results (competitive advantages, performance, profitability). The answer provided is that differences are attributable to the resources and capabilities each organization possesses (Bhatt, 2000; Fernández, Montes, \& Vázquez, 1997; Navas \& Guerras, 1998; Ventura, 1996).

Various authors have proposed what should be understood as resources (for instance, Amit \& Schoemaker, 1993; Bhatt, 2000; Wernerfelt, 1984) and what they consider a capability (for example, Amit \& Schoemaker, 1993; Barney, 2002; Bhatt, 2000; Grant, 1996). However, based on what previous authors have contributed, this research has devised its own definition about what is understood by resources and capabilities. Our approach attempts to encompass two essential aspects: (i) the strong relationship among both concepts; and (ii) the distinction among both concepts, namely:

We consider resources "the group of tangible and intangible elements or factors an organization possesses and are available to be utilized according to existing firm's capabilities that enable their best exploitation". As capabilities we understand "the group of elements or factors, intangible in nature, that are available for the organization, which enable utilization of existing resources to achieve the desired results"

The definitions above have pursued to highlight the salient fact that although an organization needs resources to execute its functions, they are not actually valuable if those capabilities that enable their adequate exploitation are not available. In this regard, we can argue that capabilities lay in a higher level than resources.

\section{Resources and Capabilities in IS/IT Organizational Context}

Within the ample variety of resources and capabilities available in an organization we find those related to IS/IT. Literature in the specific context of IS/IT has extensively treated the relationships between these systems and organizational performance or competitive advantages. This topic has 
generated increasing interest (Bergeron, Raymond \& Rivard, 2001; Devaraj \& Kohli, 2003; Tippins \& Sohi, 2003).

In literature it is also possible to find several authors that refer to resources and capabilities related to IS/IT (Bharadwaj, 2000; Dehning \& Stratopoulos, 2003; Peppard \& Ward, 2004; Teo \& Ranganathan, 2003). Bharadwaj (2000), for instance, talks about "IT resources" as the physical IT infrastructure, IT human resources (including IT technical and managerial skills) and IT based intangible resources (such as knowledge assets). She also defines "IT capabilities" as the ability to mobilize and deploy IT based resources in combination with other resources and capabilities.

\section{Definition Proposal for Resources and Capabilities Associated with IS/IT}

Earlier research underlines that, in order to accomplish and sustain increased performance, resources and capabilities related to IS/IT must be combined with other kinds of resources and capabilities (Bharadwaj, 2000; Teo \& Ranganathan, 2003), specifically, organizational, human and business resources and capabilities. Therefore, we argue that resources and capabilities directly related to IS/IT must be backed by other organizational resources and capabilities if superior performance is to be attained. This second group of resources and capabilities becomes, then, what we have termed resources and capabilities indirectly related to IS/IT.

Consequently, resources and capabilities directly related to IS/IT combined with resources and capabilities indirectly related to IS/IT, integrate what we have called in this research resources and capabilities associated with IS/IT.

Proposed definitions are described with more details in the following paragraphs:

i. Resources directly related to IS/IT: array of available tangible and intangible elements or factors directly related to the acquisition, processing, distribution and utilization of information. These elements may be utilized in accordance with the capabilities associated to IS/IT that the focal entity possesses. These resources are those located within the IS/IT organizational area. This array comprises:

- Physical IS/IT infrastructure (computers, communications technology, technical platforms, networks).

- IS/IT financial resources.

- Proprietary IS/IT technology (patent and copyright protected).

- IS/IT application and utilization experience.

- Organizational resources in the IS/IT area that may facilitate the design, development and exploitation of IS/IT. Some examples of these resources are a culture that understands technology as a supportive factor of business; fluent relations with users; close relations with external agents related to IS/IT (these might include, suppliers and/or clients related to IS/IT, and/or other organizations with which interactions are held through IS/IT); a flexible organizational structure; good reputation of IS/IT department within the organization.

- IS/IT human resources, which include IS/IT managerial staff (this incorporates both IS/IT and business knowledge and experience) and IS/IT personnel (this consists of IS/IT knowledge, experience, training, specialized skills). It also encompasses other aspects such as loyalty; motivation; commitment; technical abilities; and adaptation, communication and relationship development capabilities of both management and staff. 
ii. Capabilities directly related to IS/IT: array of available intangible elements or factors directly related to the acquisition, processing, distribution and utilization of information. These elements enable an adequate development, deployment and utilization of resources directly related to IS/IT to achieve the desired results. These capabilities are those located within the IS/IT organizational area. This array comprises:

- Technical abilities to develop and utilize IS/IT.

- Abilities to identify available opportunities for technology application.

- Skills necessary to understand the business and to visualize the way it can be supported through IS/IT.

- IS/IT managerial abilities to conceive, develop and exploit IS/IT to support organizational activities and operations.

- Ability to develop, within the IS/IT area, organizational resources that may facilitate the conception, development and utilization of IS/IT within the organization.

iii. Resources indirectly related to IS/IT: array of available tangible and intangible elements or factors that support adequate development, deployment and utilization of resources and capabilities directly related IS/IT. These elements may be utilized in accordance with the capabilities associated to IS/IT that the focal entity possesses. These resources are those located outside IS/IT organizational area. This array comprises:

- Financial resources allocated to functional areas so that they provide support to IS/IT utilization (for instance, IS/IT personnel training budget). These resources are not inside IS/IT area.

- Organizational resources outside IS/IT area, which may facilitate the conception, development and exploitation of IS/IT within the organization. These factors include an IS/IT friendly culture (change friendly culture); close relations with external agents related to IS/IT (these might include, suppliers and/or clients related to IS/IT, and other organizations with which interactions are held through IS/IT); a flexible organizational structure; good reputation of the organization as a whole due to its efficient and constructive utilization of IS/IT.

- Human resources outside IS/IT area, which include managerial staff (this incorporates both IS/IT experience and level of support towards IS/IT) and organizational personnel (this consists of IS/IT knowledge, experience, training and skills). It also encompasses other aspects such as loyalty; motivation; commitment; specialized abilities; and adaptation, communication and relationship development capabilities of both management and staff.

iv. Capabilities indirectly related to IS/IT: array of available intangible elements or factors that support adequate development, deployment and utilization of resources and capabilities directly related to IS/IT as well as resources indirectly related to IS/IT. All of these elements enable the achievement of the desired results. Capabilities indirectly related to IS/IT are located outside IS/IT organizational area. This array comprises:

- Technical abilities to utilize IS/IT (those of IS/IT users).

- Abilities to identify available opportunities for technology application.

- Skills necessary to understand the business and to visualize the way it can be supported through IS/IT. 
- Managerial abilities outside IS/IT area to conceive, develop and exploit IS/IT to support organizational activities and operations.

- Ability to develop, outside the IS/IT area, organizational resources that may facilitate the conception, development and utilization of IS/IT within the organization.

v. Resources associated to IS/IT: array of resources directly related to IS/IT and resources indirectly related to IS/IT.

vi. Capabilities associated to IS/IT: array of capabilities directly related to IS/IT as well as capabilities indirectly related to IS/IT.

Consequently, we argue that resources and capabilities associated to IS/IT are those that enable efficient development, deployment and utilization of organizational IS/IT, which, in turn, should become a supporting tool to accomplish and sustain improved organizational performance.

A graphic representation of resources and capabilities associated to IS/IT, composed of resources and capabilities directly and indirectly related to IS/IT, is provided in Figure 1.

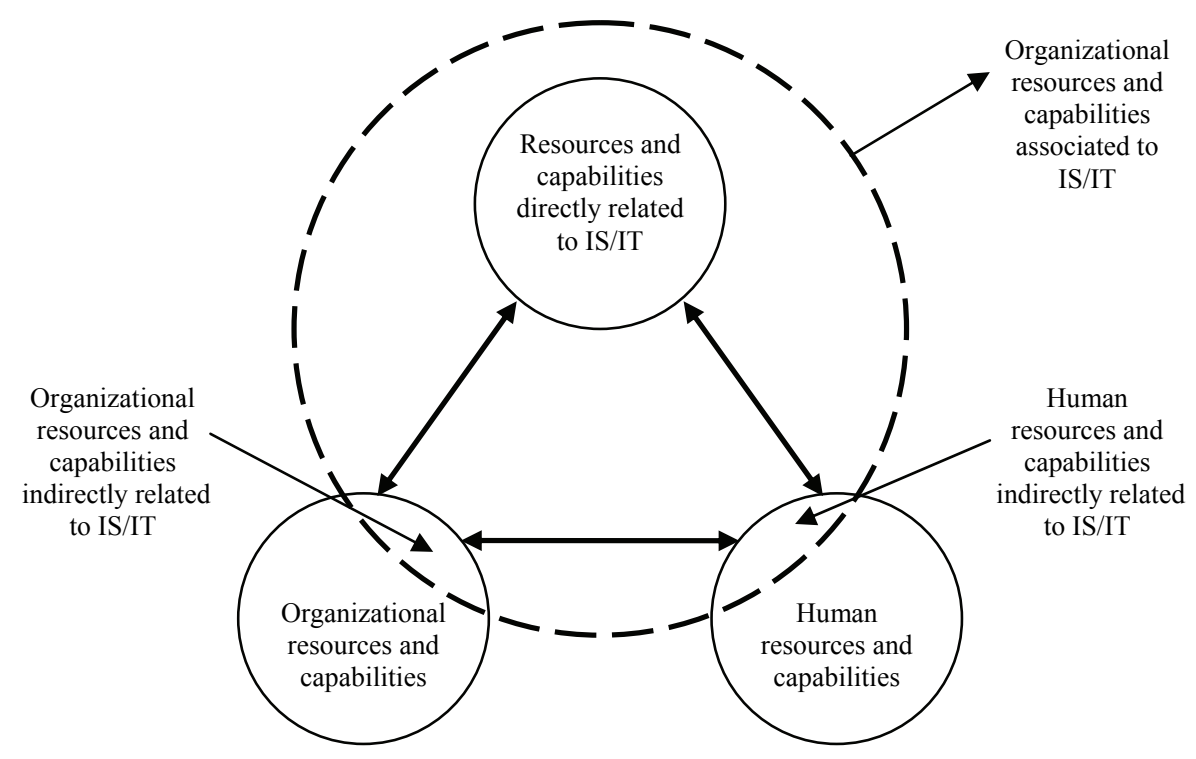

Figure 1: Conformation of resources and capabilities associated to IS/IT.

\section{Classification Proposal for Resources and Capabilities Associated with IS/IT}

Classifying resources and capabilities associated to IS/IT in two separated categorizations is a rather complex task, mainly for the following reasons:

- Many authors treat both elements as only one concept and develop a general classification (e.g. Bharadwaj, 2000; Ross, Beath \& Goodhue, 1996).

- Other researchers perform an analysis of IS/IT capabilities, but then they incorporate elements usually considered as resources in their classification (e.g. Bharadwaj, Sambamurthy \& Zmud, 1998; Ross, Beath \& Goodhue, 1996) 
- Some other authors perform an analysis of IS/IT resources, but then they incorporate elements normally considered as capabilities in their classification (Melville, Kraemer, \& Gurbaxani, 2004; Teo \& Ranganathan, 2003; Bharadwaj, 2000; Wade \& Hulland, 2004)

- Terminology used by authors is also widely varied: IT capabilities, IT assets, IT abilities, IT based resources, among others (Ross, Beath \& Goodhue, 1996)

Nevertheless, existing classifications of IS/IT resources and capabilities may be used as foundations to develop a more specific categorization. Accordingly, in order to develop our classification of resources and capabilities associated to IS/IT, we have considered the contributions of several authors on the topic, for example: Dehning \& Stratopoulos (2003), Mata, Fuerst \& Barney (1995), Teo \& Ranganathan (2003), Bharadwaj (2000), Wade \& Hulland (2004), Melville, Kraemer \& Gurbaxani (2004), among others.

After analyzing the ideas presented in each article we have identified the resources and abilities that may be related to the arguments advocated by each author. Such analysis enabled us to formulate our first and most general classification. Regarding resource categories we have identified, these comprise human resources, technological resources, organizational resources (structure, policies, rules and practices, culture), and financial resources. With respect to abilities, these pertain to three different domains: technical context, managerial context and organizational context. Therefore, the identified resources and abilities provide the basis for both classifications we propose: one for resources associated to IS/IT and another one for capabilities associated to IS/IT.

\section{Classification Proposal for Resources Associated with IS/IT}

Based on previous classifications presented in literature and on the categorization proposed by Guerras \& Navas (1998), we have devised the classification of resources associated to IS/IT that we propose in Figure 2.

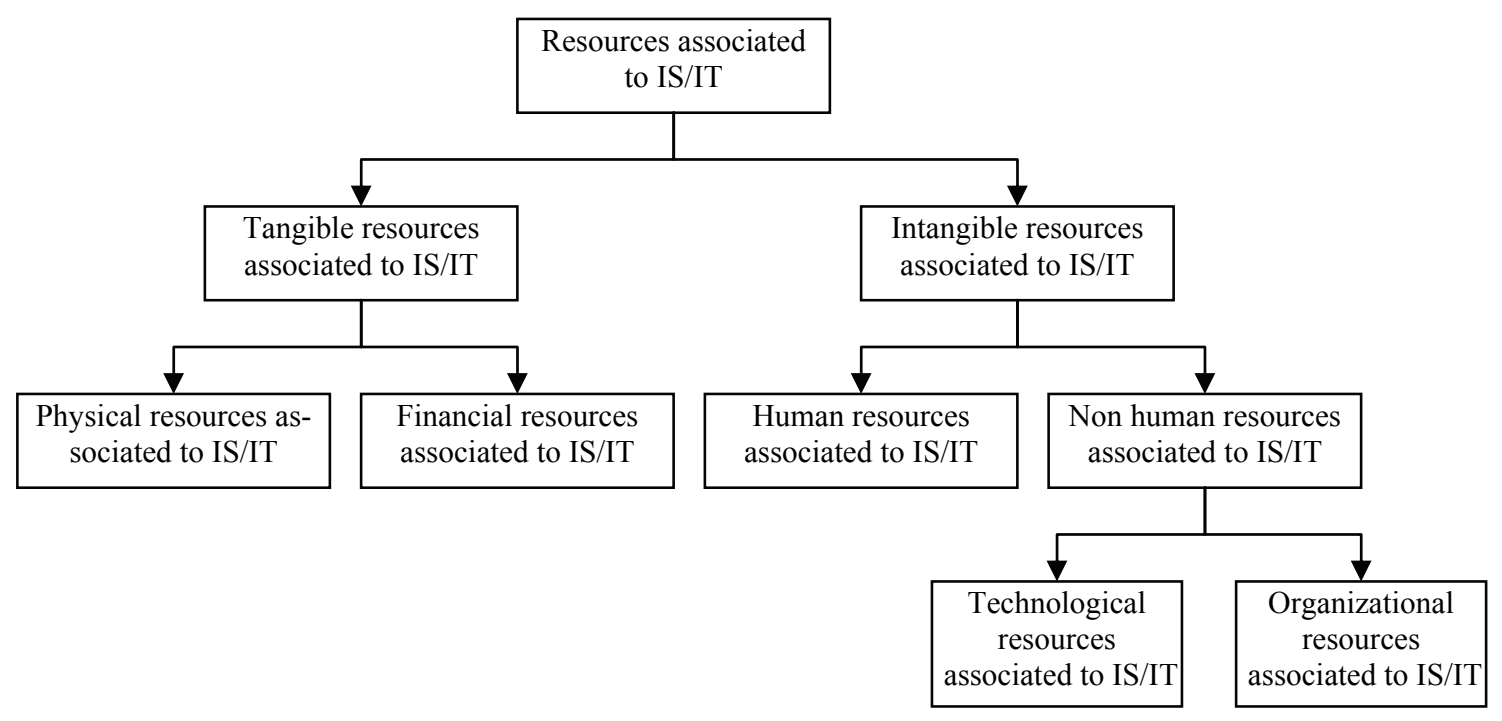

Figure 2: Classification of resources associated to IS/IT.

Source: Authors, based on resource classification proposed by Navas \& Guerras (1998)

In Tables 1 and 2 we describe the resources we have classified in Figure 2. We have arranged one table for tangible resources and another for intangible resources. 
Table 1: Description of tangible resources associated with IS/IT

\begin{tabular}{|c|c|}
\hline $\begin{array}{c}\text { GENERAL } \\
\text { CLASSIFICATION }\end{array}$ & TYPE \\
\hline Physical & $\begin{array}{l}\text { Includes all physical infrastructure related to IS/IT, Such as computers, communica- } \\
\text { tion technologies, technical platforms, networks, facilities, and others. }\end{array}$ \\
\hline Financial & $\begin{array}{l}\text { Refers to financial resources that enable development and deployment of IS/IT. It } \\
\text { encompasses financial resources allocated IS/IT area as well as funding allocated to } \\
\text { other functional areas (for instance, budget to support IS/IT utilization, human re- } \\
\text { source training outside IS/IT area). }\end{array}$ \\
\hline
\end{tabular}

Table 2: Description of intangible resources associated with IS/IT

\begin{tabular}{|c|c|c|}
\hline $\begin{array}{c}\text { GENERAL } \\
\text { CLASSIFI- } \\
\text { CATION }\end{array}$ & $\begin{array}{c}\text { SUB- } \\
\text { CLASSIFI- } \\
\text { CATION }\end{array}$ & TYPE \\
\hline $\begin{array}{l}\text { Human } \\
\text { Resources }\end{array}$ & & $\begin{array}{l}\text { Refers to human resources somehow related to IS/IT, namely: } \\
\text { - IS/IT human resources, which include IS/IT managerial staff (this incorpo- } \\
\text { rates both IS/IT and business knowledge and experience) and IS/IT person- } \\
\text { nel (this consists of IS/IT knowledge, experience, training, specialized } \\
\text { skills). } \\
\text { - Human resources outside IS/IT area, which include managerial staff (this } \\
\text { incorporates both IS/IT experience and level of support towards IS/IT) and } \\
\text { organizational personnel (this consists of IS/IT knowledge, experience, } \\
\text { training and skills). } \\
\text { Other aspects considered for both groups include loyalty; motivation; commit- } \\
\text { ment; specialized abilities; and adaptation, communication and relationship } \\
\text { development capabilities of both management and staff. }\end{array}$ \\
\hline & Technological & $\begin{array}{l}\text { Includes proprietary IS/IT technology (patent and copyright protected), IS/IT } \\
\text { utilization experience. }\end{array}$ \\
\hline $\begin{array}{l}\text { Non human } \\
\text { Resources }\end{array}$ & Organizational & $\begin{array}{l}\text { Refers to organizational resources that are necessary to develop and success- } \\
\text { fully utilize IS/IT. They may reside within and outside IS/IT area: } \\
\text { Organizational resources in IS/IT area that may facilitate design, develop- } \\
\text { ment and exploitation of IS/IT. Some examples of these resources are a cul- } \\
\text { ture that understands technology as a supportive factor of business; fluent } \\
\text { relations with users; close relations with external agents related to IS/IT } \\
\text { (these might include, suppliers and/or clients related to IS/IT, and/or other } \\
\text { organizations with which interactions are held through IS/IT); a flexible or- } \\
\text { ganizational structure; good reputation of IS/IT department within the or- } \\
\text { ganization. } \\
\text { Organizational resources outside IS/IT area, which may facilitate the con- } \\
\text { ception, development and exploitation of IS/IT within the organization. } \\
\text { These factors include an IS/IT friendly culture (change friendly culture); } \\
\text { close relations with external agents related to IS/IT (these might include, } \\
\text { suppliers and/or clients related to IS/IT, and other organizations with which } \\
\text { interactions are held through IS/IT); a flexible organizational structure; } \\
\text { good reputation of the organization as a whole due to its efficient and con- } \\
\text { structive utilization of IS/IT. }\end{array}$ \\
\hline
\end{tabular}




\section{Classification Proposal for Capabilities Associated with IS/IT}

As we pointed out, based on arguments presented in previous research, we have identified the abilities related to three different domains: technical context, managerial context and organizational context. These domains provide the basis for our classification structure. They actually give rise to each of the types of capabilities associated to IS/IT we propose. Specifically, the categories are, technical capabilities associated to IS/IT, managerial capabilities associated to IS/IT and organizational capabilities associated to IS/IT. All of these capabilities are represented in Figure 3 and are also described in Table 3.

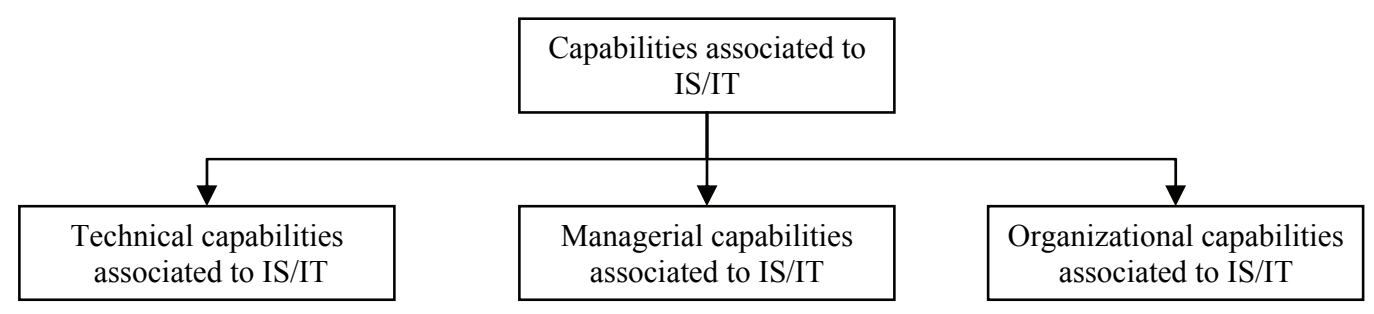

Figure 3: Classification of capabilities associated to IS/IT.

Table 3: Description of capabilities associated to IS/IT

\begin{tabular}{|c|c|}
\hline \begin{tabular}{|c|} 
CAPABILITIES \\
ASSOCIATED \\
TO IS/IT
\end{tabular} & DESCRIPTION \\
\hline $\begin{array}{l}\text { Technical } \\
\text { capabilities asso- } \\
\text { ciated to IS/IT }\end{array}$ & $\begin{array}{l}\text { They include organizational technical abilities to successfully develop IS/IT (organizational unit } \\
\text { responsible for IS/IT) and utilize IS/IT (the whole organization). It comprises the following capa- } \\
\text { bilities: } \\
\text { - Ability to properly apply knowledge and experience for developing, exploiting (IS/IT per- } \\
\text { - } \text { Annel) and utilizing (all members of the organization) IS/IT. } \\
\text { - Ability to identify available opportunities for new technology application. } \\
\text { areas and levels. These systems must fulfill organizational needs. } \\
\text { - Abilities to develop proper IT infrastructure (computers, networks, processing architectures), } \\
\text { which fulfills organizational needs. } \\
\text { - IS/IT abilities to redesign processes. } \\
\text { - Abilities to improve and innovate on existing IS/IT. } \\
\text { Abilities to implement, within IS/IT personnel, procedures that enable life-long learning in } \\
\text { technological and organizational topics. }\end{array}$ \\
\hline $\begin{array}{l}\text { Managerial capa- } \\
\text { bilities associated } \\
\text { to IS/IT }\end{array}$ & $\begin{array}{l}\text { This category comprises organizational managerial abilities (within and outside IS/IT area; but } \\
\text { most importantly within it) to conceive, develop and exploit IS/IT functions that successfully } \\
\text { support organizational activities and operations. It includes the following capabilities: } \\
\text { - Ability to develop adequate alignment among IS/IT and the firm's mission and objectives. } \\
\text { - Ability to identify, prioritize, plan, and manage IS/IT projects, according to institutional } \\
\text { needs. } \\
\text { - Ability to identify, plan, develop, allocate, coordinate and manage IS/IT resources. } \\
\text { - Ability to gain support from other members of the organization for development and utiliza- } \\
\text { - tion of IS/IT. } \\
\text { - Ability to develop appropriate consciousness about organizational mission and objectives } \\
\text { - Among IS/IT managers. } \\
\text { - Ability to demonstrate high management support and commitment towards IS/IT. } \\
\text { nal/external agents) derived from the firm's mission and objectives. } \\
\text { - IS/IT managers' ability to understand and evaluate IS/IT related needs of managers and } \\
\text { agents in other functions or areas, according to the organizational mission and objectives. }\end{array}$ \\
\hline
\end{tabular}


Table 3 (continued).

\begin{tabular}{|c|l|l|}
\hline & $\begin{array}{l}\text { This category refers to the firm's abilities to develop (within and outside IS/IT area) organizational } \\
\text { aspects that facilitate successful conception, development, and exploitation of IS/IT. It includes the } \\
\text { following capabilities: }\end{array}$ \\
$\begin{array}{c}\text { Organizational } \\
\text { capabilities as- } \\
\text { sociated to IS/IT }\end{array}$ & $\begin{array}{c}\text { IS/IT personnel ability to conceive, develop and exploit a culture that supports understanding } \\
\text { of technology as an essential tool to accomplishing institutional mission and objectives. }\end{array}$ \\
Ability to conceive, develop and exploit an IS/IT friendly culture (change friendly culture) \\
among users.
\end{tabular}

\section{Conclusions}

IS/IT evolution has increased organizational impact of these resources and capabilities. Hence, it has become increasingly relevant to define and conceptually develop the relations among those element traditionally associated to the IS/IT context and those commonly linked to other organizational domains. In this regard, the perspective we propose in this paper may be helpful to analyze the relations among IS/IT elements and other contextual resources and capabilities. A better understanding in this respect may, in turn, improve organizational members participation and collaboration in joint development and efficient utilization of IS/IT for accomplishing organizational objectives.

Resources and capabilities are two "complementary" groups of elements. Our definition of "resources and capabilities associated to IS/IT" explicitly reflects this complementarity, which unequivocally illustrates this close relationship.

Analysis of organizational resources and capabilities in general and resources and capabilities associated to IS/IT in particular, offers a rich research context. In this respect, this paper proposes an integrative starting point, which can undoubtedly be further analyzed and discussed in future research.

\section{References}

Amit, R. \& Schoemaker, P. (1993). Strategic assets and organizational rent. Strategic Management Journal, 14, 33-46.

Barney, J. (2002). Gaining and sustaining competitive advantage (2nd ed.), New Jersey: Pearson Education.

Bergeron, F., Raymond, L., \& Rivard, S. (2001). Fit in strategic information technology management research: An empirical comparison of perspectives. Omega, 29, 125-142.

Bharadwaj, A. (2000). A resource-based perspective on information technology capability and firm performance: An empirical investigation. MIS Quaterly, 24 (1), 169-196.

Bhatt, G. (2000). A resource-based perspective of developing organizational capabilities for business transformation. Knowledge and Process Management, 7 (2), 119-129.

Dehning, B. \& Stratopoulos, T. (2003). Determinants of a sustainable competitive advantage due to an ITenabled strategy. The Journal of Strategic Information Systems, 12 (1), 7-28.

Devaraj, S. \& Kohli, R. (2003). Performance impacts of information technology: Is actual usage the missing link? Management Science, 49(3), 273-289. 
Dreyer, B. \& Gronhaug, K. (2004). Uncertainty, flexibility, and sustained competitive advantage. Journal of Business Research, 57, 484-494.

Fernández, E., Montes, J., \& Vázquez, C. (1997). La competitividad de la empresa. Un enfoque basado en la teoría de recurso. Oviedo: Servicio de Publicaciones Universidad de Oviedo.

Grant, R. (1996). Dirección estratégica. Conceptos, técnicas y aplicaciones (1st ed.). Madrid: Ed. Civitas.

Mata, F., Fuerst, W., \& Barney, J. (1995). Information technology and sustained competitive advantage: A resource-based analysis. MIS Quarterly, 19 (4), 487-505.

Medina, D. (1998). Una visión integral de la empresa basada en los recursos, el conocimiento y el aprendizaje. Investigaciones Europeas de Dirección y Economía de la Empresa, 4 (2), 77-89.

Melville, N., Kraemer, K., \& Gurbaxani, V. (2004). Review: information technology and organizational performance: An integrate model of IT business value. MIS Quarterly, 28 (2), 283-322.

Navas, J. \& Guerras, L. (1998). La dirección estratégica de la empresa. Teoría y aplicaciones (2nd ed.). Madrid: Ed. Civitas.

Peppard, J. \& Ward, J. (2004). Beyond strategic information systems: Towards an IS capability. Journal of Strategic Information Systems, 13, 167-194.

Teo, T. \& Ranganathan, C. (2003). Leveraging IT resources and capabilities at the housing and development board. The Journal of Strategic Information Systems, 12 (3), 229-249.

Tippins, M. \& Sohi, R. (2003). IT competency and firm performance: Is organizational learning a missing link? Strategic Management Journal, 24 (8), 145-761.

Ventura, J. (1996). Análisis dinámico de la estrategia empresarial: un ensayo interdisciplinar. Oviedo: Servicio de Publicaciones, Universidad de Oviedo.

Wade, M. \& Hulland, J. (2004). The resource-based view and information systems research: Review, extension, and suggestions for future research. MIS Quarterly, 28 (1), 107-142.

Wernerfelt, B. (1984). A resource-based view of the firm. Strategic Management Journal, 5, 171-180.

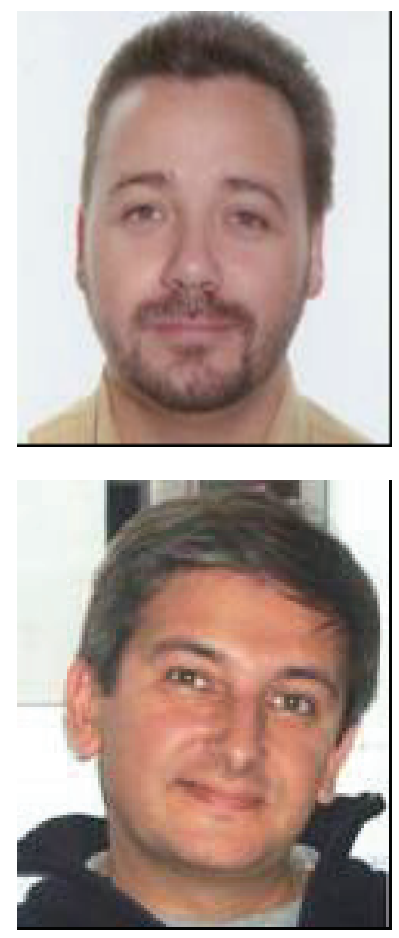

\section{Biographies}

Sergio Araya received the Electricity Technical Engineer degree in 1990 and the Computer Engineer degree in 1996. He is a professor in the Department of Information Systems at Universidad del Bío-Bío (Chile) since 1996. He is currently working on his PhD thesis in Information Systems at the Universidad Politécnica de Madrid, Spain.

Julián Chaparro received the Telecommunication Engineer degree (Hons.) in 1990 and the Ph.D degree in Information Systems (summa cum laude) in 1995, both by the E.T.S. Ingenieros de Telecomunicación of the Universidad Politécnica de Madrid. Since 1990 he is a member of the Business Administration Department of the E.T.S. Ingenieros de Telecomunicación, becoming associate professor in 1997. 


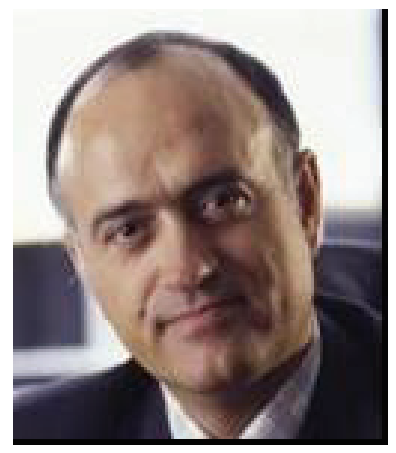

Alejandro Orero received the Telecommunication Engineer degree in 1977; a BS in Economics an Business in 1985; a Master's degree in Management Science (MS) in 1978; and a Ph.D degree in Information Systems (summa cum laude) in 1980 from the E.T.S. Ingenieros de Telecomunicación of the Universidad Politécnica de Madrid. Since 1987 he is a full Professor at the Universidad Politécnica de Madrid, Spain.

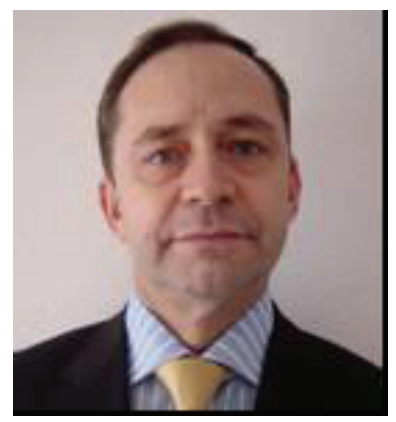

Hernán Joglar received a Bachelor of Science in Mechanical Engineering in 1999 and in Management Science in 1993. He also holds a Master of Science in Systems Engineering and Management from the Massachusetts Institute of Technology (MIT) and is currently a PhD student in Information Systems at the Universidad Politécnica de Madrid (UPM). 